\title{
Early detection of psychosis: helpful or stigmatizing experience?
}

\section{A qualitative study}

Martina Uttinger, ${ }^{1}$, Susan Koranyi ${ }^{1,2}$, Martina Papmeyer ${ }^{1,3}$, Fabienne Fend ${ }^{1}$, Sarah Ittig $^{1}$, Erich Studerus ${ }^{1}$, Avinash Ramyead ${ }^{1}$, Andor Simon $^{4}$, Anita Riecher-Rössler ${ }^{1}$

${ }^{1}$ Center for Gender Research and Early Detection, University of Basel Psychiatric Clinics, Basel, Switzerland

${ }^{2}$ Department of Medical Psychology and Medical Sociology, University of Leipzig, Leipzig, Germany

${ }^{3}$ Division of Systems Neuroscience of Psychopathology, Translational Research Center, University Hospital of Psychiatry, University of Bern, Bern, Switzerland

${ }^{4}$ Specialized Early Psychosis Outpatient Service for Adolescents and Young Adults, Department of Psychiatry, Bruderholz, Switzerland

\section{Corresponding Author:}

Prof. Anita Riecher-Rössler, MD PhD

Head of Center for Gender Research and Early Detection

Psychiatric University Clinics Basel

Kornhausgasse 7

$\mathrm{CH}-4051$ Basel, Switzerland

Tel.: +4161325 8161

Fax: +4161325 8160

E-mail: Anita.Riecher@upkbs.ch

Word count of abstract (249)

Word count of text body (2942) 


\section{Abstract}

Objective: Despite the large scientific debate concerning potential stigmatizing effects of identifying an individual as being in an at-risk mental state (ARMS) for psychosis, studies investigating this topic from the subjective perspective of patients are rare. This study assesses whether ARMS individuals experience stigmatization and to what extent being informed about the ARMS is experienced as helpful or harmful.

Method: Eleven ARMS individuals, currently participating in the follow-up assessments of the prospective Basel Früherkennung von Psychosen (FePsy; English: Early Detection of Psychosis) study, were interviewed in detail using a semi-structured qualitative interview developed for this purpose. Data were analyzed using Interpretative Phenomenological Analysis.

Results: Most individuals experiencing first symptoms reported sensing that there was "something wrong with them" and felt in need of help. They were relieved that a specific term was assigned to their symptoms. The support received from the early detection center was generally experienced as helpful. Many patients reported stigmatization and discrimination that appeared to be the result of altered behavior and social withdrawal due to the prepsychotic symptoms they experienced prior to contact with the early detection clinic.

Conclusions: The results suggest that early detection services help individuals cope with symptoms and potential stigmatization rather than enhancing or causing the latter. More emphasis should be put on the subjective experiences of those concerned when debating the advantages and disadvantages of early detection with regard to stigma. There was no evidence for increased perceived stigma and discrimination as a result of receiving information about the ARMS.

Key words: ARMS, CHR, discrimination, psychosis risk, stigma, ultra-high risk 


\section{Introduction}

Psychosis is commonly preceded by nonspecific symptoms such as inability to concentrate, depressed mood and social withdrawal. Some individuals already experience attenuated psychotic symptoms in this early phase..$^{1-3}$ For such putative early stages of psychosis, the term "at-risk mental state" (ARMS) has been coined ${ }^{4}$ and defined based on internationally established criteria. ${ }^{3,5}$ Early detection clinics aim to identify patients meeting these criteria in order to monitor their symptoms and to provide treatment as necessary. The goal is to counteract the numerous negative consequences of emerging psychotic disorders as well as to prevent onset of frank psychosis. ${ }^{6}$ Recommended treatment methods include cognitive behavioral therapy. Pharmacological interventions are suggested in case transition to psychosis occurs. ${ }^{6}$

Although ARMS patients frequently suffer from symptoms that need clinical attention, the fourth edition of the Diagnostic and Statistical Manual (DSM-IV) did not include a diagnosis covering this specific psychopathological syndrome. In the fifth edition of the Diagnostic and Statistical Manual (DSM-V), attenuated psychosis syndrome has been included only in the research section rather than in the main body. This decision was preceded by a heated debate about potential stigmatization, among other issues. ${ }^{7,} 8$ The high rates of ARMS individuals who do not transition to psychosis (64\%) compared to those who do $(36 \%)^{9,10}$ have raised concerns that early detection centers might result in a high proportion of "false positives" and unnecessary treatment, and/or contribute to fear and stigmatization ${ }^{7,11}$ although, according to a recent study12, a high proportion of ARMS who do not transition continue to experience symptoms up to 15 years later (28\% persisting ARMS symptoms, $68 \%$ other psychiatric disorders), whereas only $7 \%$ exhibit complete remission.

Stigma is commonly defined as "an attribute that is deeply discrediting and that reduces the bearer from a whole and usual person to a tainted, discounted one"13 or as "the negative attitude (based on prejudice and misinformation) that is triggered by a marker of illness". ${ }^{14}$ It has been suggested that mental health services might contribute to stigma by labeling a help-seeking individual as a "psychiatric patient" at first contact and by using diagnostic 
terms such as "schizophrenia" later on. ${ }^{15}$ In the case of risk for psychosis, the label corresponds to the ARMS. The process of "becoming aware of negative stereotypes associated with the label and identifying oneself with them" is referred to as internalized stigma, ${ }^{15}$ which has been associated with low self-esteem, depression, delayed help-seeking and poor prognosis. ${ }^{16-19}$ Expected discrimination may be as damaging as self-perceived stigmatization since it may prevent patients from participating in their lives as they otherwise would. $^{15}$

Extended surveys within the general population have shown that patients with schizophrenia are the most stigmatized among psychiatric patient groups. ${ }^{15,20-22}$ Studies focusing on the subjective perspective of patients with schizophrenia have reached the same conclusion. ${ }^{23}$ ARMS individuals who are experiencing low levels of stigma-associated stress have been shown to have a better prognosis regarding their well-being. ${ }^{24,25}$ Potential misinterpretation of ARMS as being equivalent to schizophrenia, 26 may increase the vulnerability to internalized stigma. The same holds for the tendency of adolescents and young adults (i.e., the age group at highest risk for the onset of psychotic-like symptoms) to exhibit a high level of negative stereotyping of mental illness. ${ }^{8}$ Altered behavior that is apparent to others, prior to any contact with mental health systems, ${ }^{27}$ may further worsen stigma. $^{28}$

However, there is no scientific evidence yet with regard to the often expressed concern that being informed about ARMS contributes to stigma. ${ }^{27}$ Of the few studies on the subjective perspective of those concerned, ${ }^{8,28,29}$ none focuses specifically on the questions we address here: (1) Do ARMS individuals experience any stigmatization - and if so, of what kind? (2) Do early detection centers contribute to stigmatization, or is the support provided rather seen as comforting and helpful? Therefore, this is the first qualitative study to investigate these questions specifically from the subjective perspective of ARMS individuals. 


\section{Methods}

\section{Sample}

Eleven individuals fulfilling the ARMS criteria according to the Basel Screening Instrument for Psychosis $(\mathrm{BSIP})^{30}$ were interviewed by the first author. None of them had transitioned to psychosis at the time of the interview. The sample size was determined according to the guidelines of Smith et al. ${ }^{31}$ In nine individuals, the interview took place during the follow-up assessments of the prospective FePsy study (Früherkennung von Psychosen; early detection of psychosis). We consecutively approached patients who were either receiving clinical support or had study follow-up appointments at the time (for follow-up duration see Table 1). Two patients were not participants in the FePsy study but fulfilled the ARMS criteria. ${ }^{32}$ All subjects gave written informed consent. One patient declined to participate because he did not feel sufficiently well. The sample consisted of $36 \%$ women and $64 \%$ men. Patients were on average 26 years old. Socio-demographic characteristics and psychopathology measures of the study sample are shown in Table 1.

\section{Table 1 about here}

\section{Procedure and instrument}

To the best of our knowledge, only one instrument (Personal Beliefs about Experiences Questionnaire) has been used thus far to investigate internalized stigma in ARMS individuals. ${ }^{18}$ Our aim was to specifically assess internalized stigma and additional aspects of stigma - including discrimination and coping. Therefore, we chose a qualitative approach because it appears to be most suitable to capture information about the subjective perspective. $^{33}$

Qualitative data was collected using semi-structured interviews which were conducted at the early detection center where ARMS individuals received clinical treatment. Topics derived from the literature were used as guidelines to define specific interview questions (see Table 2). To approach theoretical saturation, essential themes brought up by patients themselves were further investigated in upcoming interviews of other patients. The study was approved 
by the regional Ethics Committee (Ethikkommission Nordwest- und Zentralschweiz (EKNZ)). Interviews lasted from 20 to 60 minutes and were videotaped. Data was collected from October 2013 through March 2014.

Table 2 about here

\section{Analysis}

Interviews were transcribed and qualitative data was analyzed using the principles of Interpretative Phenomenological Analysis (IPA). ${ }^{33}$ Important statements of each transcript were selected, paraphrased and condensed using the rules of Qualitative Content Analysis. ${ }^{34}$ In total, 352 statements were systematically categorized. The resulting categories were further assigned to superordinate emerging themes. Since categories may include several statements from the same individual, the frequency of statements per category could exceed the number of participants. The interviewer assigned statements to categories and themes, which subsequently was replicated independently by one of the co-authors (F.F.) who was familiar with the data through her involvement in the transcription process. The consensus proved to be very high from the beginning, but a few adjustments were made after a discussion between the two raters (e.g. two categories were joined, one was renamed, five statements were reassigned). The number of statements per category was estimated by two independent raters. Data analysis was supervised by two of the co-authors (M.P. and A.R.R.). Study method and results are reported according to the Consolidated Criteria for Reporting Qualitative Studies (COREQ) guidelines. ${ }^{35}$

\section{Results}

Emerging themes and categories are shown in Table 3. The analysis revealed twelve emerging themes as listed below in the order presented during the interview; individual categories are featured in rank order of statement frequency. Patient frequencies were included where they differed from statement frequencies (numbers in brackets). As we 
intended to include as much data as possible into the themes and categories, we present a larger number of themes and categories than comparable qualitative studies. ${ }^{29,36,37}$

\section{Perception of first symptoms (16)}

Seven participants described mainly nonspecific symptoms, such as loss of motivation, which caused the feeling "there was something wrong with me, but I could not tell what exactly it was".

\section{Perceived triggers (24)}

Six participants perceived symptoms as resulting from stress associated with a difficult work environment. Five patients attributed the onset of symptoms to a different illness, medication side effects or drug use.

\section{Coping with symptoms (25)}

All individuals tried to cope with their symptoms in some way. Nine either attempted actively to help themselves or reported thinking "this is just temporary" and waited for symptoms to disappear. Four patients established contact with the early detection clinic mainly through specialist referral or, in some cases, through a friend or family member. Five patients clearly stated that they were in need of help at the time of the first contact.

\section{Stereotypes/images of psychosis (26)}

Even though many individuals were not familiar with the specific meaning of the term psychosis, eight had heard it before and were aware of its negative image in the public opinion and the media as well as of stereotypes about psychosis as "total loss of any ability to live a normal life" or "going mad". The following patient statement provides an example:

"There are doctors in my family who know the mental health system from their hospital internship 20 years ago [in China] [..]. There were people with slobber running out of their mouths and stuff like that. [..] My parents said "you are not going there"." 


\section{Helpful aspects of contact with the early detection center (68)}

Contact with the early detection clinic was reported as helpful by all patients. The following statements provide examples of the range of aspects perceived as helpful:

"I had an assessment of intelligence [...] and it revealed that I was above average. [...] That told me I was not stupid although I had been treated that way by other people all my life. It was a huge relief."

"Through counseling I learned that my symptoms were related to my cannabis consumption [...] and that I could get better by stopping it, which is what I did."

Further frequent statements from nine individuals included having benefited from conversations with psychologists and having acquired coping strategies. The opportunity to call the early detection center and get an appointment at any time provided ten patients with a feeling of safety. Also, ten individuals were glad to have physical illness ruled out through medical examination. Eight patients felt relieved to have their feeling "that there was something wrong" validated and named as a condition by a professional.

\section{No changes in the ability to continue life as usual after disclosure about the ARMS}

The following patient statement serves as an example for this theme:

"I was in a very bad state [when I got informed about the ARMS], so the conversation could not have made it worse. In the end, it does not matter if you know about your risk or not as long as life goes on [...]. I did not want my problems to determine my everyday life, which is why I continued living just as I did before."

\section{Negative aspects of contact with the early detection center (36)}

Seven patients reported feelings of insecurity and fear because of "not knowing what to expect" at first contact as well as immediately after being informed about the ARMS. Additionally, six patients stated that the appointments were time-consuming. Further, six patients criticized frequent changes of staff and administrative issues. 


\section{Patients' needs (16)}

Eight patients stated the need to share their personal experiences with other affected individuals and expressed an interest to participate in a group therapy or self-help group. The following statement exemplifies another frequently mentioned need:

"I needed practical strategies for everyday life. [...] I would have liked to delve deeper into this subject but there was little time to do so due to the assessment procedure with its questionnaires."

\section{Positive experiences and support in the social environment (43)}

Nine patients experienced talking about their problems and visiting the early detection center in a positive way. The same was true for the sympathy and support they had received from peers and family. Six patients discovered that other people were willing to open up about their own mental health difficulties. This helped them realize that they were not the only ones affected.

\section{Expected discrimination (30)}

While all patients told at least one close friend or family member about their problems, only three disclosed the ARMS and many used watered-down versions. Reasons for doing so included not wanting to inform others about a possible transition to psychosis as long as it was uncertain whether it would actually occur. Furthermore, eight individuals feared negative reactions in view of common stereotypes about psychosis, as the following example shows:

"If I told someone, "I have a risk of developing psychosis and perceive strange things [...]", he would be disturbed and treat me differently. I have seen people being put down as taking too many drugs. This is sad."

\section{Experienced stigma (21)}

Six individuals experienced stigmatizing reactions, e.g.:

"When I was sick [because of my mental health issues] for a few weeks a year ago, that was okay, but on renewal of my working contract they were concerned about it. [..] Although I had 
been working fine for the last five years [..]. I experienced it as unfair that they made such a big deal about it."

Friends and acquaintances of another patient smiled in an awkward manner and changed the topic when he brought up his problems. Moreover, his social withdrawal was interpreted as diminished interest in friendships.

Negative experiences with psychiatric clinics prior to contact with the early detection clinic included being "put on a waiting list for therapy for months while symptoms worsened", feeling "treated like another file on the shelf" and being "confined to a ward with drugdependent people without being diagnosed". Three participants had witnessed the involuntary confinement of affected family members into wards full of strangely behaving patients, which they experienced as frightening.

\section{Self-efficiency (26)}

Eight patients still felt in control of their actions and decisions and engaged in active coping strategies. These included adjustment of their attitudes as well as active attempts at controlling symptoms, e.g., by focusing on certain aspects of the environment while avoiding others. Patients wanted to be actively involved in their treatment and to receive information about their condition. One patient even stated he would have been more worried had the assessment not revealed something.

\section{Table 3 about here}

\section{Discussion}

In this study, eleven ARMS individuals were interviewed to investigate (1) whether they experienced any stigmatization, and if so, (2) whether early detection and being informed about the ARMS contributed to stigma or whether the support offered by an early detection clinic was perceived as helpful.

Regarding the first question, there is evidence for stigmatization. The interviewed persons were aware of common stereotypes about people with psychosis. Nevertheless, they did not 
seem to identify themselves with these but rather distanced themselves from internalized stigma. They were able to distinguish ARMS from actual psychosis and to take the uncertainty of transition into account. Both genders seemed to be affected equally. However, since all individuals in the present study had received cognitive behavioral case management for up to three years and since internalized stigma has shown to decrease with therapy, ${ }^{38}$ this mindset might result from therapy.

Other studies have shown internalized stigma in ARMS individuals to be associated with depression, social anxiety and decreased well-being. ${ }^{18,25}$ This is in line with our patients' statements of feeling insecure and in need of discussing a variety of questions after first being informed about their ARMS. Importantly, they were able to overcome this initial experience with the help of the early detection team. Likewise, studies assessing the psychological impact of at-risk states in other illnesses (e.g., cardiovascular risk, risk of cancer, etc.) have found that information about an at-risk status was related to anxiety, depression and distress in the short-run only. ${ }^{39}$ In the present study, we show that internalized stigma - if present - is mainly related to the awareness of existing stereotypes about mental illness combined with the perception that "there is something wrong with me".

In line with another study, ${ }^{40}$ fear of possible stigma due to negative stereotypes about psychosis caused many individuals to reveal their ARMS to close friends and family members only. Several reported "not being taken seriously" or "being perceived as lazy or lacking motivation" by their social environment and felt relieved to be finally perceived as having a mental health condition. It is noteworthy that most interviewed individuals were interested in sharing their experiences with other affected persons. The importance of social contact in ARMS has consistently been emphasized in studies. ${ }^{37,41}$ Although not in the entire sample, there was evidence for stigmatization caused by early symptoms and altered behavior, in particular with regard to social withdrawal.

As for our second question, whether early detection centers contribute to stigma in ARMS, patient statements revealed no such evidence. On the contrary, ARMS individuals were 
eager to learn about their condition and felt that they could continue to live a good life. This is in accordance with a previous study by Welsh and Tiffin. ${ }^{40}$ The findings summarized above suggest that the support offered by early detection centers does not contribute to stigma but rather reduces it. This is further underlined by patients' reports of generally positive experiences with the early detection clinic. ${ }^{18}$

\section{Limitations}

The double role of the interviewer as clinician and researcher may have influenced the responses of patients, who may have been reluctant to criticize the treatment staff. ${ }^{35}$ However, since participants voluntarily shared their experiences, we do not believe this to be the case. On the contrary, the trusting relationship to the psychologist may have promoted disclosure of subjective experiences. A second limitation is that, since patients were selected from a help-seeking group by convenience sampling, a positive bias is possible, in the sense that participating patients may have expressed mostly positive experiences. To counteract such a bias, explicit questions about negative experiences were included. Furthermore, helpseeking might be associated with better illness insight, which is known to be associated with higher perceived stigma. ${ }^{42,43}$ On the other hand, help-seeking individuals may receive more social support which may protect them against stigma. Another limitation of this study is the lack of a control group that would not have been informed about their at-risk state. Furthermore, ARMS individuals who do transition to psychosis could be subject to more stigmatization than individuals who do not.

\section{Conclusions}

The qualitative interviews applied in the present study yield new insights into the effects of informing patients about their ARMS. Individuals provided detailed and meaningful descriptions of their experiences. ${ }^{37}$ Patients seemed to benefit from sharing their personal views, including those regarding potential stigma. Since ARMS individuals seem to be affected by stigmatization in terms of stereotype awareness and, in some cases, experiences 
of discrimination, early detection centers play an important role in preventing and reducing stigmatization by sharing knowledge and counteracting stereotypes. Based on our results, we suggest that treatment manuals intended for use in ARMS individuals include standardized assessments of stigma (e.g. stereotype awareness, expected stigma, experienced discrimination) as well as intervention measures actively addressing stereotypes, internalized stigma and associated coping skills. Qualitative studies can serve as a base for further investigation. However, more research on this topic is clearly needed. The inclusion of the attenuated psychosis syndrome in section III of DSM-V will hopefully encourage such research.

\section{Acknowledgements}

All authors declare not to have any conflicts of interest that might have influenced the content of the manuscript. The authors of this study were supported by research grants of the Swiss National Science Foundation (SNF), the EU FP7 Project «European Network of National Schizophrenia Networks Studying Gene-Environment Interactions» (EU-GEI) and by the Stanley Medical Research Institute Foundation for the Neurapro-E (North America Europe Australia Prodrome) study. We thank all patients who participated in the interviews as well as the referring specialists and colleagues. We also would like to thank Claudine Pfister and Johannes Hapig for their help with the preparation and submission of the manuscript. 


\section{References}

1. Riecher-Rössler A, Pflueger MO, Aston J, et al. Efficacy of Using Cognitive Status in Predicting Psychosis: A 7-Year Follow-Up. Biol Psychiatry. 2009; 66: 1023-30.

2. Riecher-Rössler A, Gschwandtner U, Borgwardt S, Aston J, Pflüger M, Rössler W. Early detection and treatment of schizophrenia: how early? Acta Psychiatr Scand Suppl. 2006: 73-80.

3. Yung AR, McGorry PD. The prodromal phase of first-episode psychosis: past and current conceptualizations. Schizophr Bull. 1996; 22: 353-70.

4. McGorry PD. Schizophrenia: risk and possibility. In: Singh BS, ed. Handbook of studies on preventative psychiatry. Amsterdam: Elsevier; 1995. 491-514.

5. Fusar-Poli P, Borgwardt S, Bechdolf $A$, et al. The Psychosis High-Risk State: $A$ Comprehensive State-of-the-Art Review. Arch Gen Psychiatry. 2012: 1-14.

6. McGorry PD, Nelson B, Amminger GP, et al. Intervention in individuals at ultra-high risk for psychosis: a review and future directions. J Clin Psychiatry. 2009; 70: 1206-12.

7. Yung AR, Woods SW, Ruhrmann S, et al. Whither the attenuated psychosis syndrome? Schizophr Bull. 2012; 38: 1130-4.

8. Yang LH, Wonpat-Borja AJ, Opler MG, Corcoran CM. Potential stigma associated with inclusion of the psychosis risk syndrome in the DSM-V: an empirical question. Schizophr Res. 2010; 120: 42-8.

9. Fusar-Poli $P$, Borgwardt $S$, Bechdolf $A$, et al. The psychosis high-risk state: a comprehensive state-of-the-art review. JAMA Psychiatry. 2013; 70: 107-20.

10. Simon AE, Borgwardt S, Riecher-Rössler A, Velthorst E, de Haan L, Fusar-Poli P. Moving beyond transition outcomes: Meta-analysis of remission rates in individuals at high clinical risk for psychosis. Psychiatry Res. 2013.

11. Simon AE, Velthorst E, Nieman $D H$, Linszen D, Umbricht D, de Haan L. Ultra high-risk state for psychosis and non-transition: A systematic review. Schizophrenia Research. 2011; 132: 8-17.

12. Lin A, Wood SJ, Nelson B, Beavan A, McGorry P, Yung AR. Outcomes of nontransitioned cases in a sample at ultra-high risk for psychosis. Am J Psychiatry. 2015; 172: 249-58.

13. Goffman E. Stigma notes on the management of spoiled identity. New York: Simon and Schuster; 1986.

14. Sartorius N. Stigma and mental health. Lancet. 2007; 370: 810-1.

15. Link BG, Struening EL, Neese-Todd S, Asmussen S, Phelan JC. On describing and seeking to change the experience of stigma. Psychiatric Rehabilitation Skills. 2002; 6 : 201-31.

16. Ritsher JB, Phelan JC. Internalized stigma predicts erosion of morale among psychiatric outpatients. Psychiatry Res. 2004; 129: 257-65.

17. Ruhrmann S, Paruch J, Bechdolf $A$, et al. Reduced subjective quality of life in persons at risk for psychosis. Acta Psychiatr Scand. 2008; 117: 357-68.

18. Pyle M, Stewart SLK, French P, et al. Internalized stigma, emotional dysfunction and unusual experiences in young people ar risk of psychosis. Early Intervention in psychiatry. 2013.

19. Thornicroft G. Stigma and discrimination limit access to mental health care. Epidemiol Psichiatr Soc. 2008; 17: 14-9.

20. Gaebel W, Baumann A, Witte AM, Zaeske H. Public attitudes towards people with mental illness in six German cities: results of a public survey under special consideration of schizophrenia. Eur Arch Psychiatry Clin Neurosci. 2002; 252: 278-87.

21. van Zelst $C$. Which environments for $G \times E$ ? A user perspective on the roles of trauma and structural discrimination in the onset and course of schizophrenia. Schizophr Bull. 2008; 34: 1106-10.

22. Thornicroft G, Brohan E, Rose D, Sartorius N, Leese M, Group IS. Global pattern of experienced and anticipated discrimination against people with schizophrenia: a crosssectional survey. Lancet. 2009; 373: 408-15. 
23. Mestdagh A, Hansen B. Stigma in patients with schizophrenia receiving community mental health care: a review of qualitative studies. Soc Psychiatry Psychiatr Epidemiol. 2014; 49: 79-87.

24. Rüsch N, Heekeren $\mathrm{K}$, Theodoridou A, et al. Attitudes towards help-seeking and stigma among young people at risk for psychosis. Psychiatry Res. 2013; 210: 1313-5.

25. Rüsch N, Müller M, Heekeren $\mathrm{K}$, et al. Longitudinal course of self-labeling, stigma stress and well-being among young people at risk of psychosis. Schizophr Res. 2014; 158: 824.

26. Yang LH, Lo G, WonPat-Borja AJ, Singla DR, Link BG, Phillips MR. Effects of labeling and interpersonal contact upon attitudes towards schizophrenia: implications for reducing mental illness stigma in urban China. Soc Psychiatry Psychiatr Epidemiol. 2012; 47: 1459-73.

27. Shrivastava A, McGorry PD, Tsuang M, et al. "Attenuated psychotic symptoms syndrome" as a risk syndrome of psychosis, diagnosis in DSM-V: The debate. Indian $\mathrm{J}$ Psychiatry. 2011; 53: 57-65.

28. van Zelst C. Stigmatization as an environmental risk in schizophrenia: a user perspective. Schizophr Bull. 2009; 35: 293-6.

29. Welsh P, Tiffin PA. Attitudes of patients and clinicians in relation to the at-risk state for psychosis. Early Interv Psychiatry. 2013; 7: 361-7.

30. Riecher-Rössler A, Aston J, Ventura J, et al. [The Basel Screening Instrument for Psychosis (BSIP): development, structure, reliability and validity]. Fortschr Neurol Psychiatr. 2008; 76: 207-16.

31. Smith JA, Flowers P, Larkin M. Interpretative phenomenological analysis theory, method and research. London: SAGE; 2009.

32. Yung AR, Phillips LJ, McGorry PD, et al. Prediction of psychosis - A step towards indicated prevention of schizophrenia. Brit J Psychiat. 1998; 172: 14-20.

33. Smith JA. Interpretative phenomenological analysis and the new genetics. London: Sage Publications; 2002.

34. Mayring P. Qualitative Inhaltsanalyse Grundlagen und Techniken. 2., durchgesehene Aufl. ed. Weinheim: Deutscher Studien Verlag; 1990.

35. Tong A, Sainsbury $P$, Craig J. Consolidated criteria for reporting qualitative research (COREQ): a 32-item checklist for interviews and focus groups. Int J Qual Health Care. 2007; 19: 349-57.

36. Byrne RE, Morrison AP. Young people at risk of psychosis: Their subjective experiences of monitoring and cognitive behaviour therapy in the early detection and intervention evaluation 2 trial. Psychol Psychother. 2013.

37. Hardy KV, Dickson JM, Morrison AP. Journey into and through an early detection of psychosis service: the subjective experience of persons at risk of developing psychosis. Early Interv Psychiatry. 2009; 3: 52-7.

38. Morrison AP, Birchwood M, Pyle M, et al. Impact of cognitive therapy on internalised stigma in people with at-risk mental states. Br J Psychiatry. 2013; 203: 140-5.

39. Shaw C, Abrams K, Marteau TM. Psychological impact of predicting individuals' risks of illness: a systematic review. Soc Sci Med. 1999; 49: 1571-98.

40. Welsh P, Tiffin PA. Observations of a small sample of adolescents experiencing an atrisk mental state (ARMS) for psychosis. Schizophr Bull. 2012; 38: 215-8.

41. Welsh P, Tiffin PA. Experience of child and adolescent mental health clinicians working within an at-risk mental state for psychosis service: a qualitative study. Early Interv Psychiatry. 2012; 6: 207-11.

42. Lysaker PH, Roe D, Yanos PT. Toward understanding the insight paradox: internalized stigma moderates the association between insight and social functioning, hope, and selfesteem among people with schizophrenia spectrum disorders. Schizophr Bull. 2007; 33: 192-9.

43. Staring $A B$, Van der Gaag M, Van den Berge $M$, Duivenvoorden HJ, Mulder CL. Stigma moderates the associations of insight with depressed mood, low self-esteem, and low quality of life in patients with schizophrenia spectrum disorders. Schizophr Res. 2009; 115: 363-9. 
44. Ventura J, Lukoff D, Nuechterlein K, Liberman R, Green M, Shaner A. Manual of the expanded brief psychiatric rating scale. Int J Methods Psychiatr Res. 1993: 227-43.

45. Andreasen NC. The scale for the assessment of negative symptoms (SANS):

Conceptual and theoretic foundations. Brit J Psychiat. 1989; 155: 49-52.

Table 1: Sample description

\begin{tabular}{lccccc}
\hline & Total & Women & Men & $\mathrm{p}$ & $\mathrm{N}$ \\
\hline Gender (\%) & $\mathrm{N}=11$ & $\mathrm{~N}=4(36)$ & $\mathrm{N}=7(64)$ & & \\
Age mean (SD) & $26.7(7.72)$ & $23.0(2.16)$ & $28.8(9.11)$ & 0.16 & 11 \\
Occupation: & & & & \\
Employed & 4 & 1 & 3 & \\
Education (university student) & $5(3)$ & $3(2)$ & $2(1)$ & \\
Unemployed & 2 & 0 & 2 & \\
BPSR total score mean (SD) & $31.7(5.29)$ & $31.7(8.14)$ & $31.7(4.27)$ & 1.00 & 9 \\
SANS total score mean (SD) & $8.27(8.81)$ & $6.69(6.36)$ & $9.06(10.3)$ & 0.69 & 9 \\
Follow-up duration mean (SD) & $10.5(10.0)$ & $5.80(4.42)$ & $13.1(11.6)$ & 0.17 & 9 \\
(months) & & & & & \\
$\geq 36$ & 2 & 0 & 2 & & \\
12 & 2 & 0 & 2 & & \\
6 & 1 & 1 & 3 & &
\end{tabular}

BPRS: Brief Psychiatric Rating Scale ${ }^{44}$, SANS: Scale for the Assessment of Negative Symptoms ${ }^{45}$ 
Table 2: Topics covered by the qualitative interview

1. Experience of first symptoms (cognitive, affective)

2. Experience of first contact with the early detection center (cognitive, affective)

3. Experience of the information received regarding ARMS (cognitive, affective)

4. Reactions of the social environment to disclosures regarding contact with the early detection center and ARMS

5. Experience of the ARMS:

a) Helpful aspects

b) Disadvantages, discrimination, stigmatization and coping with such

c) Experience of assessment and treatment received in the early detection center 
Table 3: Emerging themes and categories with frequencies $†$

\begin{tabular}{|c|c|c|c|}
\hline Emerging theme & $\mathbf{F}$ & Category & $\mathbf{F}$ \\
\hline \multirow{4}{*}{$\begin{array}{l}\text { 1. Perception of } \\
\text { first symptoms }\end{array}$} & \multirow[t]{4}{*}{16} & Nonspecific symptoms, loss of motivation, social withdrawal & $10(7)$ \\
\hline & & $\begin{array}{l}\text { There was something wrong with me, I had changed but did not } \\
\text { know how or why }\end{array}$ & 7 \\
\hline & & Symptoms started step by step and worsened gradually & 5 \\
\hline & & Sudden bizarre changes in perception or thinking & 2 \\
\hline \multirow{3}{*}{$\begin{array}{l}\text { 2. Perceived } \\
\text { triggers }\end{array}$} & \multirow{3}{*}{24} & Stress due to difficult work conditions & $9(6)$ \\
\hline & & Other illness (e.g., autism, flu) & $4(2)$ \\
\hline & & Medication (antidepressants)/drugs & 3 \\
\hline \multirow[t]{3}{*}{$\begin{array}{l}\text { 3. Coping with } \\
\text { symptoms }\end{array}$} & \multirow[t]{3}{*}{25} & $\begin{array}{l}\text { Attempts to help oneself, passively waiting for situation to get } \\
\text { better failed }\end{array}$ & $13(9)$ \\
\hline & & I needed help & $8(5)$ \\
\hline & & $\begin{array}{l}\text { Contact with the early detection center via referral or with help } \\
\text { of family member or friend }\end{array}$ & 4 \\
\hline \multirow{4}{*}{$\begin{array}{l}\text { 4. Images of } \\
\text { psychosis/ } \\
\text { stereotypes }\end{array}$} & \multirow[t]{4}{*}{26} & No specific image of psychosis although the term is familiar $\dagger$ & $10(8)$ \\
\hline & & $\begin{array}{l}\text { Loss of reality or consciousness/"going mad"/worse than other } \\
\text { psychiatric disorders }\end{array}$ & $9(4)$ \\
\hline & & "Invisible illness" & 5 \\
\hline & & Similar to experiences when taking drugs & 2 \\
\hline \multirow{5}{*}{$\begin{array}{l}\text { 5. Helpful aspects } \\
\text { of contact with } \\
\text { the early } \\
\text { detection clinic }\end{array}$} & \multirow[t]{5}{*}{68} & $\begin{array}{l}\text { Helpful information/motivation to change behavior/improvement } \\
\text { of situation }\end{array}$ & $19(9)$ \\
\hline & & $\begin{array}{l}\text { Assessment and presence of psychologists and doctors } \\
\text { provides feeling of security }\end{array}$ & $14(10)$ \\
\hline & & $\begin{array}{l}\text { Relief that others could also see what I felt and that they could } \\
\text { name it }\end{array}$ & $14(8)$ \\
\hline & & Staff was nice and friendly & $11(8)$ \\
\hline & & $\begin{array}{l}\text { I was not left alone/somebody listened to me/l was taken } \\
\text { seriously }\end{array}$ & $10(5)$ \\
\hline \multirow[t]{2}{*}{ 6. No changes } & \multirow[t]{2}{*}{21} & $\begin{array}{l}\text { Knowing about my condition did not change symptoms, I } \\
\text { continued as before. It is better not to worry too much }\end{array}$ & $18(7)$ \\
\hline & & Focus on other diagnosis, ARMS secondary & $3(2)$ \\
\hline \multirow[t]{4}{*}{$\begin{array}{l}\text { 7. Negative } \\
\text { aspects }\end{array}$} & \multirow[t]{4}{*}{36} & $\begin{array}{l}\text { "First contact was strange, new, I did not know what was in } \\
\text { store for me, I was stressed" }\end{array}$ & $13(7)$ \\
\hline & & $\begin{array}{l}\text { Information about the ARMS at first shocking, put symptoms } \\
\text { into focus }\end{array}$ & $9(5)$ \\
\hline & & $\begin{array}{l}\text { Appointments for assessment and study were time-consuming } \\
\text { and psychologically draining }\end{array}$ & 6 \\
\hline & & Difficulties with changing staff, administrative issues & 6 \\
\hline \multirow[t]{2}{*}{$\begin{array}{l}\text { 8. Needs of } \\
\text { patients }\end{array}$} & \multirow[t]{2}{*}{16} & $\begin{array}{l}\text { Exchange of experiences with other affected individuals/group } \\
\text { therapy }\end{array}$ & $8(6)$ \\
\hline & & Need for treatment and support for everyday life & 8 \\
\hline \multirow{2}{*}{$\begin{array}{l}\text { 9. } \begin{array}{l}\text { Positive } \\
\text { experiences/ } \\
\text { support }\end{array} \\
\end{array}$} & \multirow[t]{2}{*}{43} & $\begin{array}{l}\text { Positive or neutral reactions and support in the social } \\
\text { environment when talking about symptoms and therapy }\end{array}$ & $35(9)$ \\
\hline & & I am not the only one affected by mental health issues & $8(6)$ \\
\hline \multirow[t]{2}{*}{$\begin{array}{l}\text { 10. Expected } \\
\text { discrimination }\end{array}$} & \multirow[t]{2}{*}{30} & $\begin{array}{l}\text { Not talking openly about the ARMS, talking exclusively to close } \\
\text { friends or relatives, or using a diminished version of problems }\end{array}$ & $17(8)$ \\
\hline & & $\begin{array}{l}\text { It is a taboo in society? What would others think of me? Why } \\
\text { does this happen to me? }\end{array}$ & $13(8)$ \\
\hline \multirow[t]{2}{*}{$\begin{array}{l}\text { 11. Experienced } \\
\text { discrimination }\end{array}$} & \multirow[t]{2}{*}{21} & $\begin{array}{l}\text { Negative experiences with the mental health system (own } \\
\text { experiences or with family/friends) }\end{array}$ & $10(7)$ \\
\hline & & Negative reactions of the social environment & $11(6)$ \\
\hline \multirow[t]{3}{*}{ 12.Self-efficiency } & \multirow[t]{3}{*}{26} & Active coping strategies & $14(8)$ \\
\hline & & My own decisions and strategies were required and helpful & $6(4)$ \\
\hline & & I want to know about my condition & 6 \\
\hline
\end{tabular}

$\dagger$ Patient frequencies are stated in parentheses if different from statement frequencies 